\title{
What's what in organic chemistry
}

\section{E.R.H. Jones}

\begin{abstract}
Heilbron's Dictionary of Organic Compounds, 5th Edn. Executive editor J. Buckingham. Seven volumes, pp.7,848. ISBN 0-412-17000-0. (Chapman \& Hall/ Methuen: 1982.) $£ 975, \$ 1,950$.
\end{abstract}

THE number of compounds described in the literature provides a more precise measure of the growth of chemistry than publications or other indicators. Organic chemistry, thanks to the tetravalency of carbon and the stability of its incestuous bonds, is responsible for most of these compounds; even the recent plethora of inorganic compounds is attributable to organic coordinating components. The number is now nearly five million and, resulting from advances in techniques, many recent additions have large and complicated structures. Remarkably, however, this situation is being coped with.

Some 50 years ago Professor Ian Heilbron and H.M. Bunbury recognized the need of chemists for something akin to the Concise Oxford, and the first edition of the Dictionary of Organic Compounds (1934), a most successful venture, provided a readily accessible source of information. "Heilbron" is the first point of enquiry for many, and this fifth edition (the fourth appeared in 1965) is timely indeed. The need for facile reference to the literature has never been greater.

In the new edition the original policy of encompassing all of interest and importance is more specifically defined; the intention has been to include fundamental compounds of simple structure, the majority of important natural products, compounds of commercial value, and laboratory chemicals and those with special chemical, physical or biological properties. Selection of the 50,000 entries, by deletion as well as addition, which overall results in the mention of about 1 in 30 of known compounds, has been satisfactorily achieved with the assistance of a hundred chemists, including some 20 special editors, all experts.

With this highly organized team and using modern methods of data handling, the selection and compilation of information and production of the books were completed within five years so that the primary literature has been covered to the end of 1980. Although the new edition involves "the most radical revision and modernisation", the traditional format, the generous provision of structural formulae and indeed all the familiar features have been retained. And there are significant changes. Citing only one author's name is a sensible economy and specifying the content of references (e.g., isol, synth, struct, cmr and so on) is a valuable innovation, as is the extensive inclusion of toxicity and hazard indications and references.
Organic chemists think in terms of structural formulae and need assistance to translate these into dictionary entries. Help is abundantly available from the molecular formulae and name indexes. Alternative and recommended names are given, indication of their sources is useful and Chemical Abstracts Registry Numbers provide a nomenclature-independent link to, and from, those printed here and to the other services which are increasingly using Registry Numbers. A heteroatom index, in 62 sections, points to the entries containing elements other than $\mathrm{C}, \mathrm{H}, \mathrm{O}, \mathrm{N}$ and halogens. Thus we find amongst the 1,500 organo-metallic compounds 19 of copper and 25 of manganese. Accessibility to the alphabetical entries from the indexes is enormously facilitated by serial numbers for each entry, and will be most helpful with the annual supplements (the first promised for 1983).

By comparison with the cost of periodicals and other books, the seven volumes and 7,800 pages represent excellent value for scarce library money. The Dictionary is an essential adjunct wherever organic compounds are used, nowhere more so than in educational establishments where students need training to cope with the population explosion in organic chemistry.

Sir Ewart Jones is Emeritus Professor of Chemistry at the University of Oxford.

\section{The bones of palaeopathology}

\section{D.R. Brothwell}

Identification of Pathological Conditions in Human Skeletal Remains. By Donald J. Ortner and Walter G.J. Putschar. Pp.479. (Smithsonian Institution Press/US Government Printing Office: 1982.) Pbk $\$ 12$.

TWENTY-five years ago, as a young graduate of University College London, I was puzzled and impressed by the near total eclipse of interest in sub-fossil skeletal remains, and especially the evidence of palaeopathology which could be found in them. A quarter of a century earlier, in Egypt and eventually at the same college, Sir Grafton Elliot Smith and colleagues had produced distinguished studies on thousands of skeletons and mummies, paying close attention to the evidence of disease. Yet in my time, bones were a matter of considering the many scraps of fossil hominids or were simply used in the general teaching of comparative vertebrate anatomy.

The balance of interests in the biology of man is ever changing, however, with the result that human disease ecology and even such highly specialized topics as the problems of identifying disease in excavated skeletal remains is receiving renewed attention. Evidence of this, if evidence were needed, is this handsome largeformat book by two of the senior names in palaeopathology.

Considering the vast literature on medical diagnosis, one might imagine that there were sufficient references to the differential diagnosis of skeletal disease. What had Elliot Smith, Ruffer, Wood Jones and all the other golden oldies used? The answer is that they made do with rather limited texts and similarly limited dry bone specimens in medical museums, and with a range of clinical experience of bone patho$\operatorname{logy}$ in those pre-antibiotic times. But museum displays are changing (if not shrinking) and dry bones are no longer priority exhibits. It was thus becoming critical that some detailed stock-taking was undertaken, preferably with an eventual published text and "atlas" of good illustrations in mind.

These changes then, and the growing literature on bone pathology, demanded an up-to-date review of the subject, preferably with a large range of well-selected, high-quality illustrations. Although a number of introductory texts and two symposium proceedings appeared in the 1960 s, the definitive reference work of the kind provided by Ortner and Putschar remained a much needed project. This is a well-illustrated, carefully researched collaborative effort providing a comprehensive review of pathological conditions that affect the human skeleton. Having seen the authors in action, scanning the Royal College of Surgeons collection in London, I can vouch for the care with which they have not only surveyed past literature, but personally examined a very wide range of specimens of known diagnosis. There are thus authoritative details of a wide range of diseases affecting the skeleton, from congenital abnormality, trauma and arthropathy, to endocrine and metabolic disturbances, circulatory disorders and the numerous divisions of infectious disease (including less well known bone pathology, the result of mycotic infections, brucellosis, sarcoidosis and echinococcosis).

There is no doubt that this volume is an essential reference work for all those who handle ancient human skeletal material. It should also hold interest for medical historians as well as radiologists, pathologists and orthopaedic specialists.

Don Brothwell is Reader in Zooarchaeology a the Institute of Archaeology, London. 